\title{
Effective Regulation of Polycaprolactone Molecular Weight and Oligomers Content Using Tetraphenyltin Catalyst
}

\begin{abstract}
Caihong Gong ${ }^{\mathrm{ac}}$, Jinxia $\mathrm{Li}^{\mathrm{b}}$, Chunwang $\mathrm{Yi}^{* \mathrm{ac}}$, Shuanglin Qu*b
There is a lack of effective approaches that produce polycaprolactone materials (PCL) with a high molecular weight, narrow polymer dispersity index (PDI), and fewer formation of oligomers. The immigration of the remained oligomers predominantly causes poor PCL quality and induces odor release. This limits the extensive application of PCL materials. This study investigates the effects of different catalysts and loadings on the PCL performance along with the formation of oligomers in detail. The oligomers were successfully separated using gel permeation chromatography (GPC). This was followed by a quantitative and qualitative identification using high-resolution mass spectrometry (HRMS) and low field nuclear magnetic (L-field NMR) analysis. The results show that tetraphenyltin is an effective catalyst to promote the reaction and produce high-performance PCL that possesses the highest Mn (65000), narrowest PDI (1.37), and the lowest content of oligomers (7.466 wt.\%). Density functional theory (DFT) studies that were combined with characterizing key intermediates verified that an anhydride bond was formed close to the end hydroxyl group in the PCL chain because of the special catalytic mechanism. This unusual chemical structure successfully inhibited the chain from being broken by the "back-biting" behavior, which is helpful for lowering the content of oligomers. This study can provide a scalable synthetic approach to creating high-performance polymers.
\end{abstract}

\section{Introduction}

The main paragraph text follows directly on here. Polycaprolactone $(\mathrm{PCL})$ has various biological applications, such as being a controlled drug release carrier, ${ }^{[1-4]}$ fluorescent probe, ${ }^{[5]}$ cell-encapsulation device, ${ }^{[6]}$ tissue culture bed frame, ${ }^{[7-11]}$ biological dye, ${ }^{[12]}$ and medical modeling material. ${ }^{[8,}$ 13-16] This is because of its excellent biodegradation ${ }^{[17-19]}$ and biocompatibility. ${ }^{[20-22]}$ Several studies have reported that minimal water, oxygen, and hydroxy compounds can initiate the ring-opening polymerization of caprolactone. ${ }^{[23]}$ However, this can only produce low molecular weight PCL in the absence of a catalyst. Similarly, most catalysts such as diisopropyl amino lithium, ${ }^{[24]}$ stannous octoate, ${ }^{[25]}$ and organic acid tin [Sn $\left.(\mathrm{OTf})_{2}\right]^{[26]}$ insignificantly influence synthesis during caprolactone polymerization. These catalysts can only be used to prepare $\mathrm{PCL}$ with a molecular weight $(\mathrm{Mn})$ varying from 4000 to 15200 . Furthermore, most of the prepared PCLs have a wide polymer dispersity index (PDI) owing to the generation of

\footnotetext{
a. Key Laboratory of Sustainable Resources Processing and Advanced Materials of Hunan Province, Hunan Normal University, Changsha, Hunan 410081, P. R. China

b. College of Chemistry and Chemical Engineering, Hunan University, Changsha, Hunan 410082, P. R. China

c. National \& Local Joint Engineering Laboratory for New Petro-chemical Materials and Fine Utilization of Resources, Hunan Normal University, Changsha, Hunan 410081, P. R. China

E-mail: cwyi@hunnu.edu.cn; squ@hnu.edu.cn
}

oligomers, or the simultaneous polymerization and degradation during polymerization. Although hosphazene bases can generate $\mathrm{PCL}$ with a high $\mathrm{Mn}(\approx 38000)$, the conversion rate was only $14 \%$ when reacting with caprolactone for more than 10 days at 80 oC. [27] Methylaluminoxanetrimethylaluminium is a rare catalyst that can increase the $\mathrm{Mn}$ of PCL to 223800. ${ }^{[28]}$ However, the "back-biting" side reaction is competitive with the caprolactone polymerization process. This generates cyclic oligomers and makes the PCL similar to polyamide 6 (PA6), ${ }^{[29]}$ which contains certain quantities of oligomers. The authors did not investigate the mechanic performance of the prepared $\mathrm{PCL}$ and the negative effects of cyclic oligomers on the PCL properties further.

The solubility in organic solvents and the melting point of oligomers were close to PCL. This made the substances difficult to separate. Generally, the remaining oligomers can damage the material performance and release unpleasant odors after migrating progressively to the surface of the materials. This limits the application and development of PCL significantly. ${ }^{[30]}$ Recent developments in technology include gel permeation chromatography (GPC) and mass spectrum (MS) technologies. These approaches have been used to identify and determine the oligomers. ${ }^{[31-32]}$ However, an effective method to suppress the formation of oligomers have not been proposed. Therefore, significant challenges exist in PCL performance improvement, especially for the regulation of the content of 
oligomers, molecular weight, and PDI of the PCL. Therefore, a new technology using a tetraphenyltin $\left(\mathrm{Ph}_{4} \mathrm{Sn}\right)$ catalyst to prepare high-performing $\mathrm{PCL}$ is reported in this study. The molecular weight and the mechanical properties of $\mathrm{PCL}$ and the oligomer content could be conveniently regulated through varying tetraphenyltin loadings. Furthermore, characterization of key reaction intermediates and density functional theory (DFT) studies revealed the detailed reaction mechanism and verified that the catalyst can effectively suppress the formation of oligomers.

\section{Experiment}

\subsection{Polymerization}
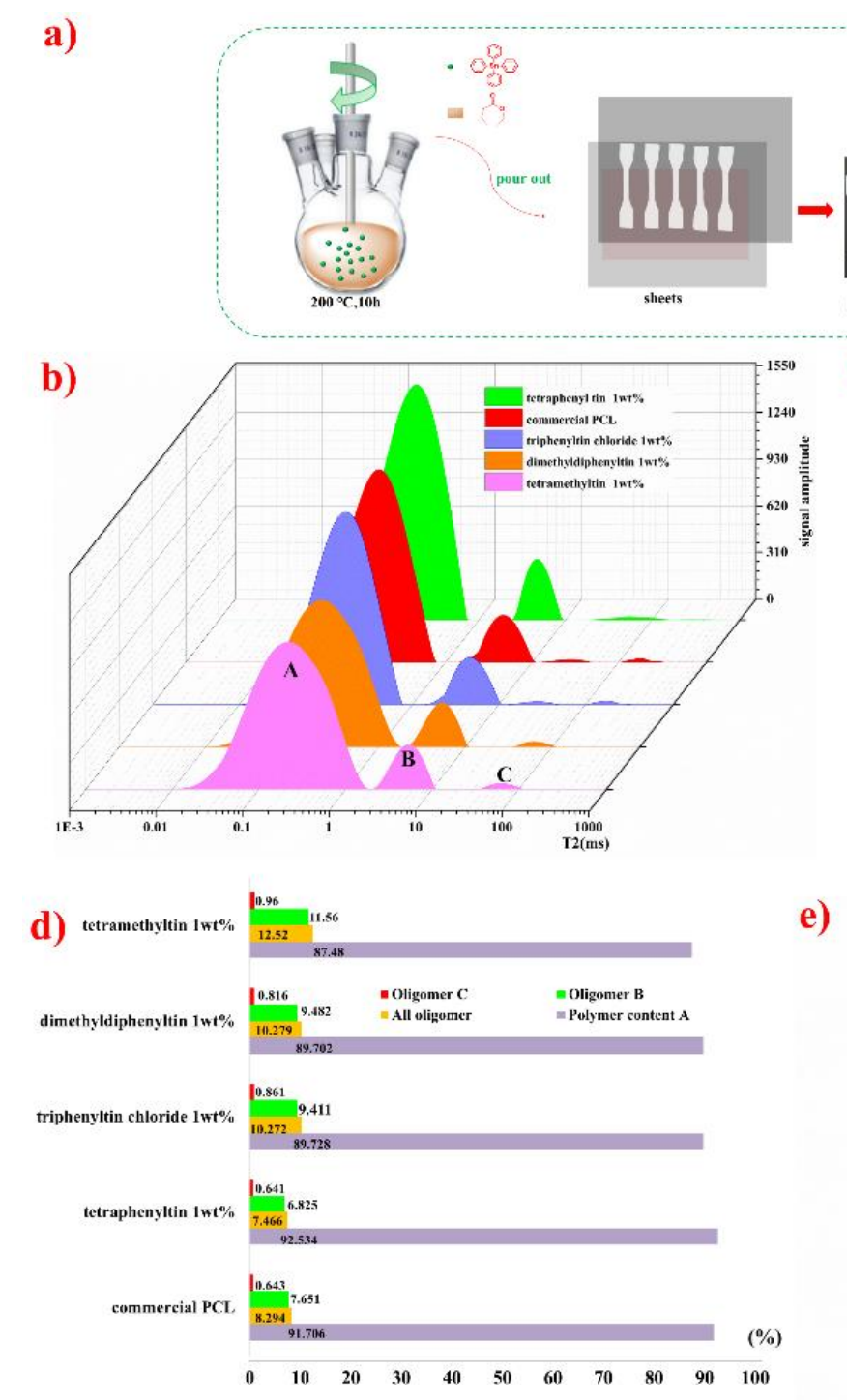

e)

The polymerization tests were performed using a "one-pot" method. Caprolactone and catalyst were added to a four-neck round bottle in a fixed mass ratio. Polymerization followed at $200{ }^{\circ} \mathrm{C}$ for $10 \mathrm{~h}$ in nitrogen air according to the synthetic approach shown in Fig. 1(a). Catalysts with different steric hindrance, such as tetraphenyltin, triphenyltin chloride, dimethyldiphenyltin, and tetramethyltin, were selected to synthesize the PCL. The main influencing factors of the polymerization process were investigated. These include the effects of different reaction times $(2-14 \mathrm{~h})$, temperature $\left(100-240^{\circ} \mathrm{C}\right)$, and catalyst dosage $(0.1-5 \%$ by weight) on the polymerization process. Other reactions were avoided using nitrogen protection that was used in the experiment. After synthesized, the products were pulverized into fine particles and dried to a constant weight at $40{ }^{\circ} \mathrm{C}$ in vacuum conditions for further analysis. All reaction process parameters are listed in Table S1.
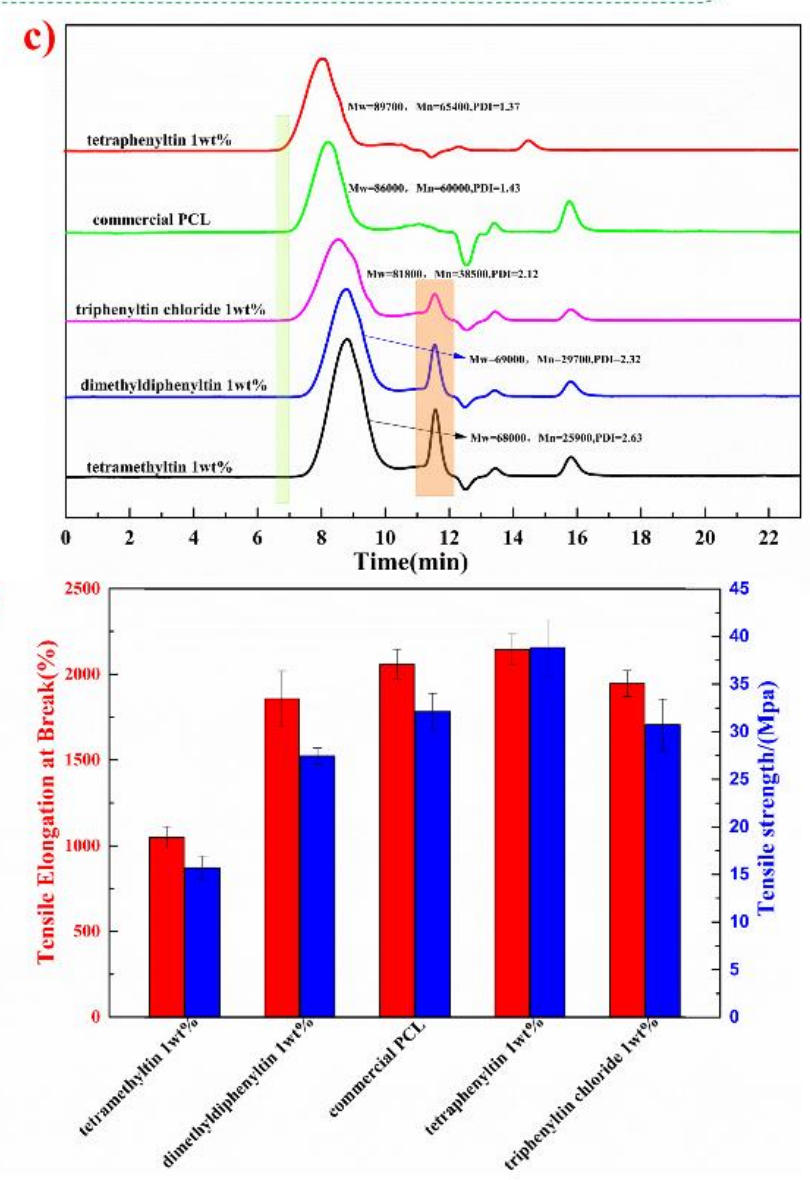
Figure 1. a) Synthesis route, Dumb-bell samples before and after tensile strength test (tetraphenyltin catalyst). b) Low field NMR patterns: "A" means long chain segment, "B" and "C" means small molecular chain segment. c) GPC curves. d) Highresolution mass spectrogram

of oligomers.

e) Mechanical properties.

\section{Results and discussion}

The conclusions section should come in this section at the end of the article, before the acknowledgements. The PCL properties were obtained using a $1 \mathrm{wt} . \%$ catalyst mass ratio under the same reaction conditions $\left(200^{\circ} \mathrm{C}, 10 \mathrm{~h}\right)$. These are displayed in Fig. 1 and Table S2. The GPC results (Fig. 1(c)) show that the tetraphenyltin system produces $\mathrm{PCL}$ with the highest $\mathrm{Mn}$ (65000) and the narrowest PDI (1.37). Additionally, small peaks appeared during the retention time of 11-16 min. This demonstrated that a certain number of oligomers with a molecular weight of less than 2000 was produced during the PCL synthesis. ${ }^{[33]}$ The content of polymers and oligomers in the $\mathrm{PCL}$ was measured further using low field nuclear magnetic ( $L$ field NMR) analysis. ${ }^{[34]}$ This indicated that the tetraphenyltin catalyzed PCL has the lowest oligomers content (7.466 wt.\%, Fig. 1(b)), which is comparable to that of the current commercial PCL. However, the PCL resulted from tetraphenyltin catalyst is vastly superior to other lab-prepared PCLs that were produced by using the other three catalysts and most reported catalysts. ${ }^{[23,25]}$ Furthermore, the results indicate that the oligomers content greatly influences the properties of the PCL. Higher content of oligomers leads to worse mechanical properties. Notably, the strain-stress tests show that the elongation and tensile strength of the tetraphenyltin catalyzed $\mathrm{PCL}$ reached $2000 \%$ and $38.5 \mathrm{MPa}$, respectively (Fig. $1(\mathrm{a}, \mathrm{e})$ ). This is also significantly better than current commercial (and the other lab-prepared) products. Especially, compared to the reported products with best elongation of $900 \%$, the elongation is remarkably increased []. Besides, the tetraphenyltin catalyzed PCL was stable without peculiar smell after exposed to natural condition for half a year. However, the other lab-prepared PCLs released odor after only being kept for days, owing to the immigration of the remained oligomers.Therefore, tetraphenyltin is the best catalyst for producing $\mathrm{PCL}$ polymer that has optimum properties. The optimum process conditions for the $P C L$ preparation were investigated further. A $1 \mathrm{wt} . \%$ dosage of tetraphenyltin was maintained for $10 \mathrm{~h}$ at $200{ }^{\circ} \mathrm{C}$ (Fig. 1, Table S2, and Table S3).

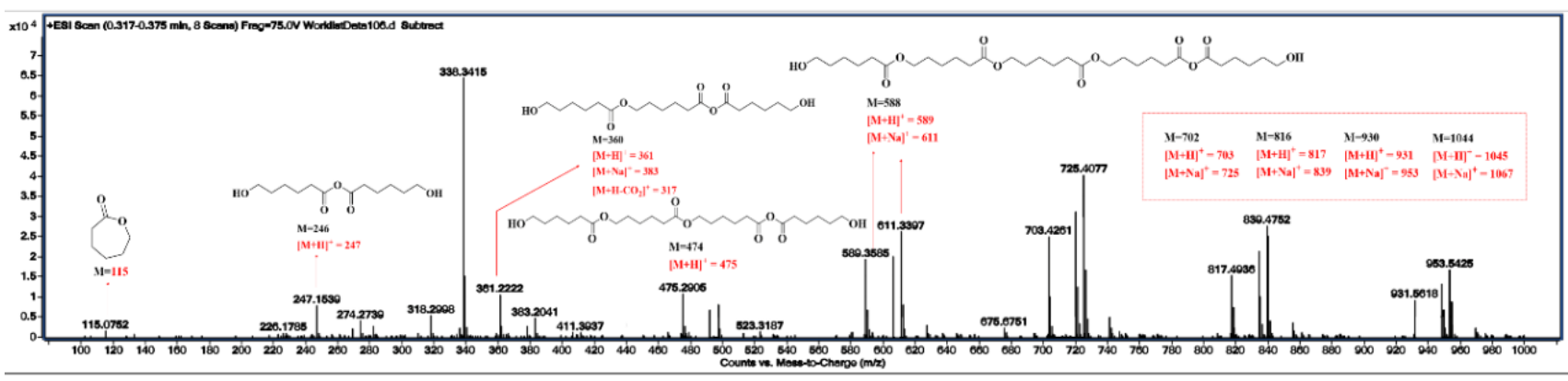

Figure 2. High-resolution mass spectrogram of oligomers.

The components related to small $p \epsilon$ the GPC analysis (Fig. 1(c)) were collecte Fig. 2 is the pattern of the high-resoluti (HRMS) that shows that there is a caprolactone in the components. Previo that the active end groups (i.e., hydrox can attack the ester or amide bonds in through "back-biting". This results in cyc shown in Fig. S1. ${ }^{[23,29]}$ However, the cycl and other typical cyclic oligomers of Fig mass spectra.

Additionally, ionic fragment peaks that the linear oligomers with the regularity spectra. Possible chemical structures are new anhydride bond (CO-O-CO) ve catalytic mechanism was involved in $t$
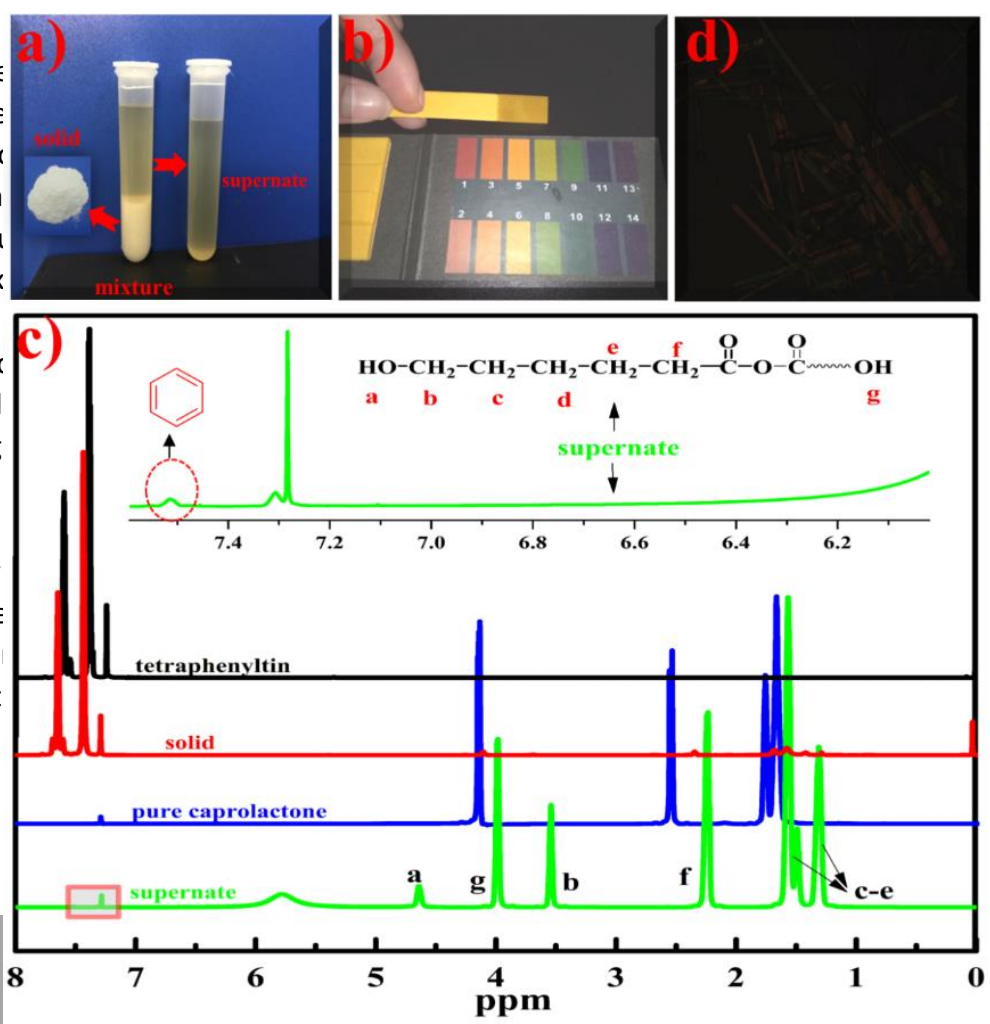

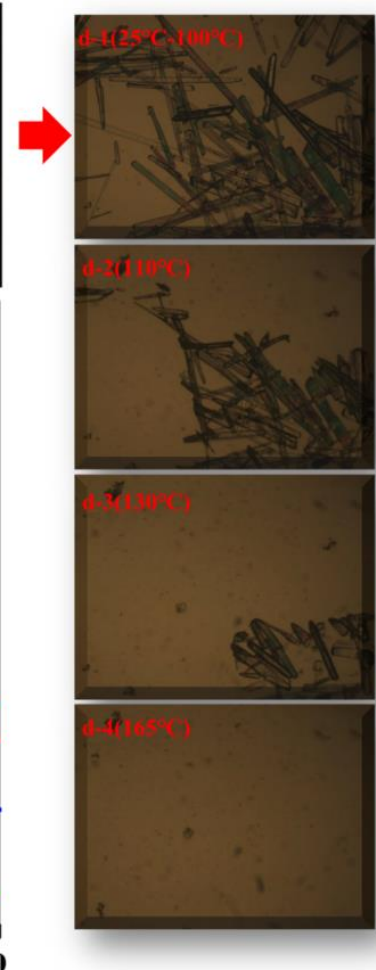


been proved through DFT calculations and will be discussed in detail in the following sections. The HRMS result shows that the "back-biting" behavior of the end hydroxyl groups has been effectively restricted, thereby significantly reducing the generation of cyclic oligomers. ${ }^{[35]}$

A well-designed experiment was performed to study the possible mechanism for the formation of PCL. White intermediates were generated after the caprolactone, and tetraphenyltin reacted at $120^{\circ} \mathrm{C}$ for $10 \mathrm{~h}$ in a four-neck round bottle (Fig. 3(a)). Fig.3(b) shows that the supernate is acidic. The separated intermediates and supernate were further analyzed using proton nuclear magnetic resonance $\left({ }^{1} \mathrm{H}-\mathrm{NMR}\right)$. Fig. 3(c) presents the $1 \mathrm{H}-\mathrm{NMR}$ patterns ofbenzene has fallen off the catalyst. The characteristic absorption peaks of hydroxyl and methylene in $\mathrm{PCL}$ are observed, which indicates the presence of linear oligomers.

Figure 3. a) Intermediate product. b) $\mathrm{pH}$ test of supernate. c) Proton nuclear magnetic resonance $\left({ }^{1} \mathrm{HNMR}\right)$ spectra of the bottom solid, supernate, pure caprolactone, and tetraphenyltin. d) Polarizing heat table microscope (POM) image of the separated bottom solid. ( 1 1 - 4) Melting behaviors of intermediates under POM at different temperatures.

The intermediates refract colorful light under polarized consistent with the experimental results that showed a small optical microscopy (Fig. 3(d)), which indicates that the intermediates consist of regular crystals. The crystals began to melt at $110^{\circ} \mathrm{C}$ and disappeared at $165{ }^{\circ} \mathrm{C}$ (Fig. 3(d 1-4)) using hot stage heating. Furthermore, the differential scanning calorimetry (DSC) analysis verifies that the intermediate has a broad melting peak at 164.7 ${ }^{\circ} \mathrm{C}$ (Fig. S2). This is not an indication of pure tetraphenyltin (melt point $=228.53{ }^{\circ} \mathrm{C}$, Fig. S3) or $\mathrm{PCL}$ (melt point $=55.74{ }^{\circ} \mathrm{C}$, Fig. S4). Furthermore, polymerized caprolactone at $240{ }^{\circ} \mathrm{C}$ for $10 \mathrm{~h}$ without using a catalyst only produced a PCL with an $\mathrm{Mn}$ of 15300 (Table S2). Therefore, the assumption is made that the intermediates are a complex of tetraphenyltin and pre-polymers. Consequently, tetraphenyltin is significant in accelerating the reaction.

Combining the above experimental results, DFT calculations ${ }^{[36]}$ were performed to gain further mechanistic insights into this transformation. The possible reaction mechanism is depicted in Fig. 4, which follows the "coordination-insertion" pathway that was reported in several previous studies for the ringopening transesterification polymerization (ROTEP) of cyclic ester catalyzed by other singlesite metal alkoxide complexes. ${ }^{[37-42]}$ The best catalyst used in this study is tetraphenyltin. The calculations show that the direct insertion of the phenyl group of tetraphenyltin into the coordinated ester monomer has to cross an extremely high activation barrier $(45.4 \mathrm{kcal} / \mathrm{mol}$, supporting information (SI)). Therefore, the tetraphenyltin complex is the precatalyst that requires an initiation process to form a real active catalyst (tin-alkoxide complex). The proposed mechanism for catalyst initiation process is shown in Fig. 4(a). First, the small amount of water in the system initiates the caprolactone ring-opening under heat, which results in carboxylic acid. Thereafter, a protodemetalation step undergoes with the carboxylic acid

providing the proton. This leads to the tin-carbonate complex and releases a benzene ring from the tin center. This is

(a)<smiles>O=C(O)C1CCCCC1=O</smiles>

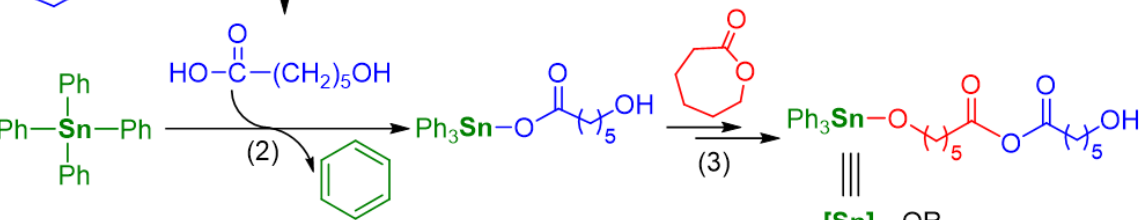

(Catalyst Initiation)

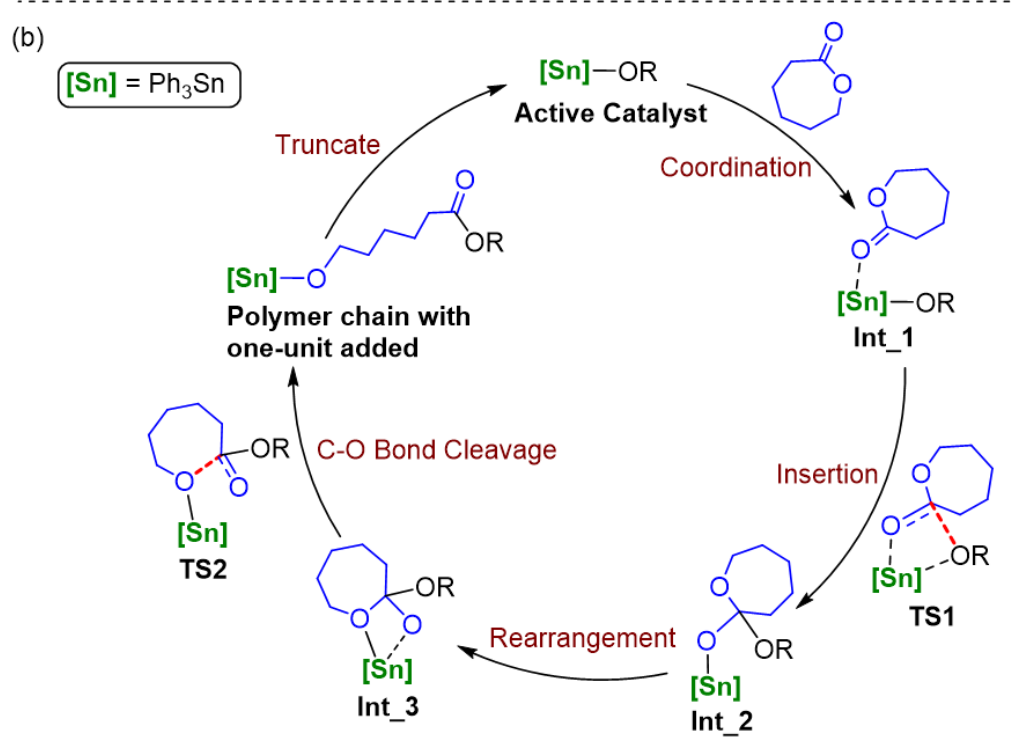

amount of benzene. Subsequently, another molecule of caprolactone reacts with the tin-carbonate complex to form the tin-alkoxide complex. This is an active catalyst for the following propagation process. Notably, step 3 of Fig. 4(a) shows that an anhydride bond (CO-O- $\mathrm{CO}$ ) was formed at the end of the tin-alkoxide complex. This aligns with the cationic fragment structure that is shown in Fig. 2. This step follows the "coordination-insertion" pathway, and the corresponding energetic details are given in the SI. 


\section{ARTICLE}

Figure 4. (a) Proposed mechanism for catalyst initiation process. (b) "Coordination-insertion" mechanism for the propagation.

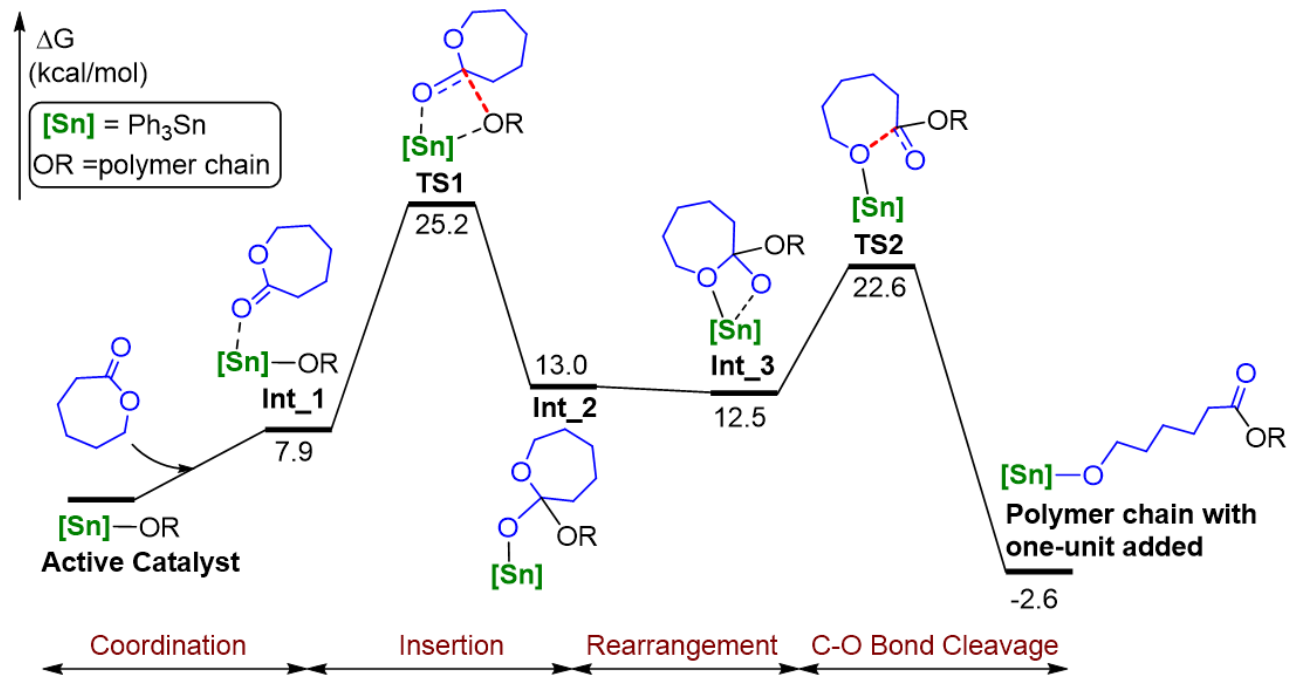

Figure 5. Free energy profile of propagation process along the "coordination-insertion" pathway. 


\section{ARTICLE}

Fig. 4(b) shows the "coordination-insertion" mechanism for the propagation process. The corresponding free energy profile is given in Fig. 5. Initially, the coordination of caprolactone to the tin center forms a precomplex (Int_1), which increases the free energy by $7.9 \mathrm{kcal} / \mathrm{mol}$. The insertion of the alkoxyl group into the activated caprolactone monomer follows via TS1, which crosses a free energy activation barrier of $25.2 \mathrm{kcal} / \mathrm{mol}$. Subsequently, the tetrahedral intermediate is rearranged by rotating around the $\mathrm{C}-\mathrm{O}$ bond (Int_2 to Int_3).
This results in the oxygen atom in the ring approaching the tin center, which decreases the free energy by $0.5 \mathrm{kcal} / \mathrm{mol}$. The $\mathrm{C}-\mathrm{O}$ bond cleavage then undergoes through TS2 with a free energy activation barrier of $22.6 \mathrm{kcal} / \mathrm{mol}$. Thereby completing the ring-opening process and generates the polymer chain alkoxide terminus that is elongated by one unit. The overall propagation step is thermodynamically favorable with a free energy decrease of $2.6 \mathrm{kcal} / \mathrm{mol}$, in which the turnover-limiting (TOL) step is the insertion step.

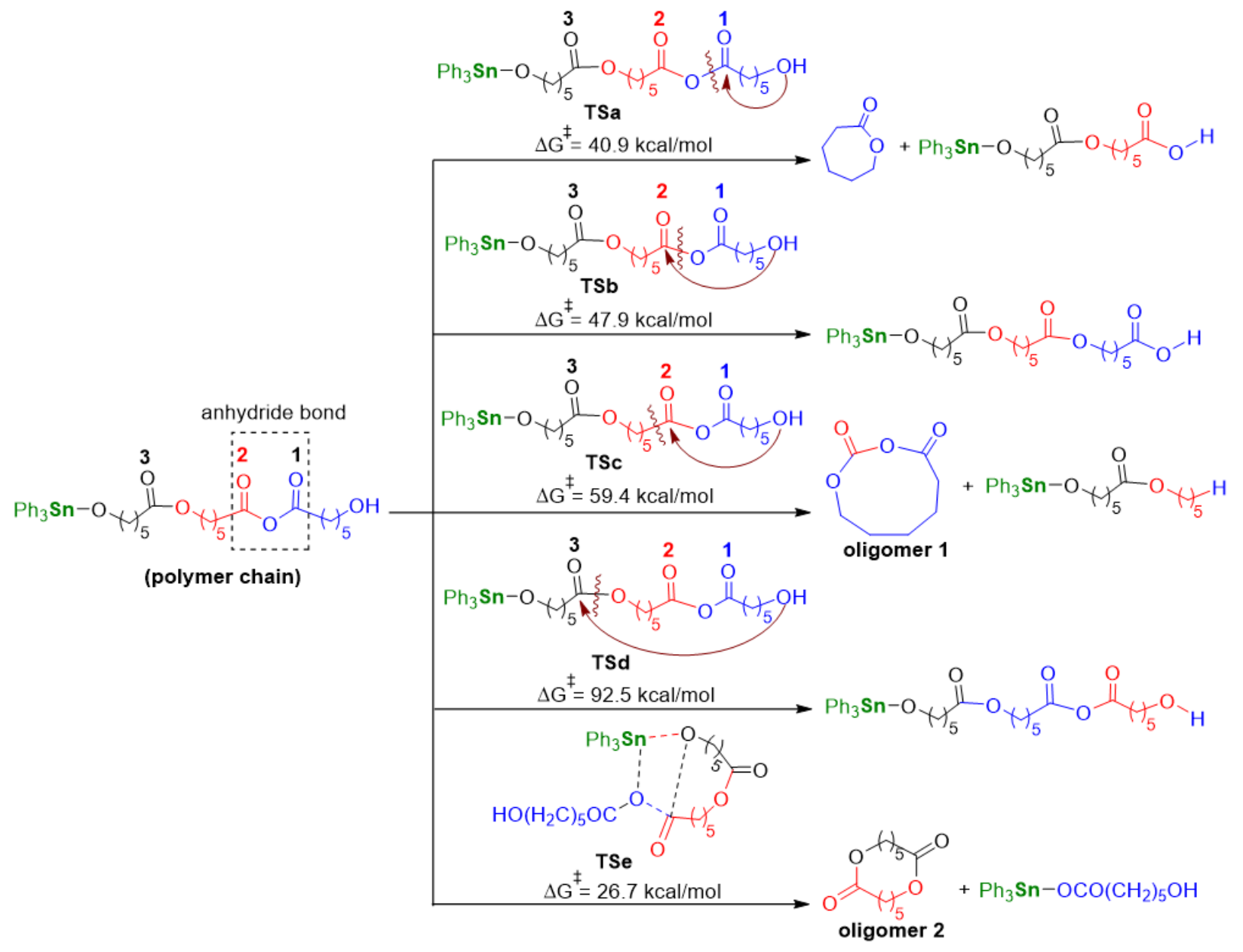

Figure 6. Possible “back-biting” reactions of the tetraphenyltin catalytic system.

The tetraphenyltin catalyst shows good experimental performance for suppressing the formation of oligomers. Generally, the oligomers are caused by the "back-biting" side reactions. Therefore, all possible "back-biting" modes for the tetraphenyltin catalyst were examined. Fig. 6 shows that the activation barriers of all "back-biting" modes of the hydroxyl terminal at either the anhydride bond (TSa, TSb, TSc) or the further ester bond (TSd) are very high ( $>40 \mathrm{kcal} / \mathrm{mol})$. Among these "back-biting" modes (TSa-TSd), only TSc could produce a cyclic oligomer side product (oligomer 1). However, TSc can be excluded because of the extremely high activation barrier $(59.4 \mathrm{kcal} / \mathrm{mol})$. Therefore, the "back-biting" of the terminal hydroxyl group is unlikely to occur and generate oligomers. 
Another typical "back-biting" reaction that causes cyclic oligomers for most previous catalytic systems is the "backbiting" of the terminal ester bond at the metal-oxygen bond (see SI). The current Sn(IV) system has an anhydride bond at the terminal end of the polymer chain. The "back-biting" of the anhydride bond at the Sn-oxygen bond occurs through TSe, which leads to a cyclic oligomer side product (oligomer 2). Although the activation barrier of TSe $(26.7 \mathrm{kcal} / \mathrm{mol})$ is 1.5 $\mathrm{kcal} / \mathrm{mol}$ less favorable than that of the insertion (ratelimiting) step for propagation (TS1, $25.2 \mathrm{kcal} / \mathrm{mol}$ ), the formation of the low content of cyclic oligomers could not be fully excluded. This corresponds to the experimental observation (oligomers content of 7.466 wt.\%.). The "backbiting" at the $\mathrm{Sn}-\mathrm{O}$ bond of the internal ester bond of the polymer chain is even more unfavorable with a higher activation barrier of $29.9 \mathrm{kcal} / \mathrm{mol}$ (Fig. S9 in SI). The relative free energies of these two transition states ("back-biting" and

\section{Conclusions}

In summary, this study effectively solved an ongoing trade-off between the high molecular weight, narrow PDI, and low content of oligomers when preparing PCLs. Tetraphenyltin is the best catalyst for preparing high-performance $\mathrm{PCL}$ that possesses the highest $\mathrm{Mn}$ (65000), narrowest PDI (1.37), and the lowest content of oligomers (7.466 wt.\%). Furthermore, the elongation and tensile strength reached $2000 \%$ and 38.5 $\mathrm{MPa}$, respectively. This is significantly better than the reported and other lab-prepared products. Additionally, by combining the characterization of key intermediates and DFT studies, the detailed reaction mechanism was determined to follow the coordination-insertion pathway. DFT studies further revealed that all possible "back-biting" modes that can generate cyclic oligomers were less favorable than the propagation process. This sufficiently supports the effectiveness of the tetraphenyltin catalyst to suppress the formation of oligomers. Furthermore, this catalyst showed similar performance in synthesizing PA6 using caprolactam as starting monomers, which is still ongoing in our lab. Therefore, this work could provide a scalable synthetic approach towards highperformance polymers.

\section{Conflicts of interest}

The authors declare no competing financial interest.

\section{Acknowledgements}

This research was supported by the National Key Research Program of China (grant number 2016YFB0302702); National Natural Science Foundation of China (21903022); Scientific Research Foundation of Hunan Provincial Education Department (grant numbers 17A126); and the Open insertion) were also compared for a previous typical Sn(II) catalyst. ${ }^{[43]}$ These free energies deliver comparable results. The insertion is only slightly more favorable $(0.5 \mathrm{kcal} / \mathrm{mol})$ than the "back-biting" (Fig. S10 in SI), indicating that the "back-biting" side reaction is competitive with the propagation process in the $\mathrm{Sn}$ (II) system. This rationalizes that the Sn(II) catalyst is not effective as the current $\mathrm{Sn}(\mathrm{IV})$ catalyst to suppress the formation of cyclic oligomers. Overall, in the current Sn(IV) catalytic system, the end hydroxyl group is unlikely to experience "back-biting" at the adjacent anhydride bond or the further ester bond, which generates oligomers. Furthermore, another type of "back-biting" at the Sn-O bond by either the terminal anhydride bond or the internal ester bond is also less favorable than the insertion step for the propagation process. The above-calculated results sufficiently verify that the current Sn(IV) catalyst efficiently restricts oligomer formation.

Foundation of National \& Local Joint Engineering Laboratory for New Petro-chemical Materials and Fine Utilization of Resources (grant numbers KF201804). We also sincerely thank Mr. Yi Yang, manager of Su Zhou Newman Analytical Instrument Company to provide low field nuclear magnetic test.

\section{References}

1 Chang, S. H.; Lee, H. J.; Park, S.; Kim, Y.; Jeong, B., Fast Degradable Polycaprolactone for Drug Delivery. Biomacromolecules 2018, 19 (6), 2302-2307.

2 Doan-Nguyen, T. P.; Natsathaporn, P.; Jenjob, R.; Niyom, Y.; Ittisanronnachai, S.; Flood, A.; Crespy, D., Regulating Payload Release from Hybrid Nanocapsules with Dual Silica/Polycaprolactone Shells. Langmuir 2019, 35 (35), 11389-11396.

3 Rashad, A.; Mohamed-Ahmed, S.; Ojansivu, M.; Berstad, K.; Yassin, M. A.; Kivijarvi, T.; Heggset, E. B.; Syverud, K.; Mustafa, K., Coating 3D Printed Polycaprolactone Scaffolds with Nanocellulose Promotes Growth and Differentiation of Mesenchymal Stem Cells. Biomacromolecules 2018, 19 (11), 4307-4319.

4 Ding, F.; Mou, Q.; Ma, Y.; Pan, G.; Guo, Y.; Tong, G.; Choi, C. H. J.; Zhu, X.; Zhang, C., A Crosslinked Nucleic Acid Nanogel for Effective siRNA Delivery and Antitumor Therapy. Angew. Chem. Int. Ed. 2018, 57 (12), 3064-3068.

5 Kulkarni, B.; Jayakannan, M., Fluorescent-Tagged Biodegradable Polycaprolactone Block Copolymer FRET Probe for Intracellular Bioimaging in Cancer Cells. ACS Biomater. Sci. Eng. 2017, 3 (9), 2185-2197.

6 Faleo, , C. E. N. R. C. G.; Kevin D. Lance, D. A. B., Qizhi Tang,; Desai, T. A., Polycaprolactone Thin-Film Micro- and Nanoporous Cell-Encapsulation Devices. ACS Nano 2015, 9 ( 6), 5675-5682.

7 Reddy, C. S.; Venugopal, J. R.; Ramakrishna, S.; Zussman, E., Polycaprolactone/oligomer compound scaffolds for cardiac tissue engineering. J. Biomed. Mater. Res., Part A 2014, 102 (10), 3713-3725.

8 Bhatt, S.; Pulpytel, J.; Mirshahi, M.; Arefi-Khonsari, F., Catalyst-Free Plasma-Assisted Copolymerization of Poly( $\varepsilon$ caprolactone)-poly(ethylene glycol) for Biomedical Applications. ACS Macro Lett. 2012, 1 (6), 764-767.

9 Liu, X.; Miller, A. L.; Fundora, K. A.; Yaszemski, M. J.; Lu, L., Poly( $\varepsilon$-caprolactone) Dendrimer Cross-Linked via Metal-Free 
Click Chemistry: Injectable Hydrophobic Platform for Tissue Engineering. ACS Macro Lett. 2016, 5 (11), 1261-1265.

10 Wang, D.; Jang, J.; Kim, K.; Kim, J.; Park, C. B., "Tree to Bone": Lignin/Polycaprolactone Nanofibers for Hydroxyapatite Biomineralization. Biomacromolecules 2019, 20 (7), 26842693.

11 No, Y. J.; Castilho, M.; Ramaswamy, Y.; Zreiqat, H., Role of Biomaterials and Controlled Architecture on Tendon/Ligament Repair and Regeneration. Adv. Mater. 2020, 32 (18), 1904511-1904527.

12 Su, M.; Li, S.; Zhang, H.; Zhang, J.; Chen, H.; Li, C., NanoAssemblies from J-Aggregated Dyes: A Stimuli-Responsive Tool Applicable To Living Systems. J. Am. Chem. Soc. 2019, 141 (1), 402-413.

13 Sharifi, F.; Patel, B. B.; Dzuilko, A. K.; Montazami, R.; Sakaguchi, D. S.; Hashemi, N., Polycaprolactone Microfibrous Scaffolds to Navigate Neural Stem Cells. Biomacromolecules 2016, 17 (10), 3287-3297.

14 Santillán, J.; Dwomoh, E. A.; Rodríguez-Avilés, Y. G.; Bello, S. A.; Nicolau, E., Fabrication and Evaluation of Polycaprolactone Beads-on-String Membranes for Applications in Bone Tissue Regeneration. ACS Appl. Bio Mater. 2019, 2 (3), 1031-1040.

15 Kim, S. E.; Wang, J.; Jordan, A. M.; Korley, L. T.; Baer, E.; Pokorski, J. K., Surface Modification of Melt Extruded Poly(epsilon-caprolactone) Nanofibers: Toward a New Scalable Biomaterial Scaffold. ACS Macro Lett. 2014, 3 (6) 585-589.

16 Pati, F.; Gantelius, J.; Svahn, H. A., 3D Bioprinting of Tissue/Organ Models. Angew. Chem. Int. Ed. 2016, 55 (15), 4650-65.

17 Sanabria-DeLong, N.; Aamer, K. A.; Agrawal, S. K.; Bhatia, S. R.; Tew, G. N., Poly(lactide)-Poly(ethylene oxide)Poly(lactide) Triblock Copolymers: Synthesis and Thermal Properties. In Degradable Polymers and Materials; American Chemical Society: Washington, DC, 2006; pp 156-167.

18 Minna Hakkarainen, A.-C. A., Heterogeneous Biodegradation of Polycaprolactone - Low Molecular Weight Products and Surface Changes. Macromol. Chem. Phys. 2002, 203, 13571363.

19 Zhu, Y.; Poma, A.; Rizzello, L.; Gouveia, V. M.; Ruiz-Perez, L.; Battaglia, G.; Williams, C. K., Metabolically Active, Fully Hydrolysable Polymersomes. Angew. Chem. Int. Ed. 2019, 58 (14), 4581-4586.

20 Zheng, Q.; Li, J.; Yuan, W.; Liu, X.; Tan, L.; Zheng, Y.; Yeung, K. W. K.; Wu, S., Metal-Organic Frameworks Incorporated Polycaprolactone Film for Enhanced Corrosion Resistance and Biocompatibility of $\mathrm{Mg}$ Alloy. ACS Sustainable Chem. Eng. 2019, 7 (21), 18114-18124.

21 Mahesh Kumar Joshi, A. P. T., Hem Raj Pant, Bishnu K Shrestha, Han Joo Kim, Chan-Hee Park, Cheol Sang Kim, In Situ Generation of Cellulose Nanocrystals in Polycaprolactone Nanofibers: Effects on Crystallinity, Mechanical Strength, Biocompatibility, and Biomimetic Mineralization. ACS Appl. Mater. Interfaces 2015, 7 (35), 19672-19683.

22 Williams, D. F., Biocompatibility Pathways: BiomaterialsInduced Sterile Inflammation, Mechanotransduction, and Principles of Biocompatibility Control. ACS Biomater. Sci. Eng. 2016, 3 (1), 2-35.

23 Labet, M.; Thielemans, W., Synthesis of polycaprolactone: a review. Chem. Soc. Rev. 2009, 38 (12), 3484-3504.

24 Shaheen Motala-Timol, A. B.-L., Dhanjay Jhurry, Kinetic Study of the Al-Schiff's Base Initiated Polymerization of $\varepsilon$ caprolactone and Synthesis of Graft Poly(methylmethacrylate-g-caprolactone). Macromol. Symp. 2006, 231, 69-80
25 Sherman, R. F. S. J. W., Kinetics and Mechanism of the Stannous Octoate-Catalyzed Bulk Polymerization of $\varepsilon$ Caprolactone. Macromolecules 2002 35, 1504-1512.

26 Hedrick, M. M. R. K. J. L., Sn(OTf)2 and Sc(OTf)3: Efficient and Versatile Catalysts for the Controlled Polymerization of Lactones. J. Polym. Sci. Part A: Polym. Chem. 2000, 38 (11) 2067-2074.

27 Lei Zhang, F. N., Russell C. Pratt, Robert M. Waymouth, James L. Hedrick, and Charles G. Wade, Phosphazene Bases: A New Category of Organocatalysts for the Living RingOpening Polymerization of Cyclic Esters. Macromolecules 2007, 40, 4154-4158.

28 Florjańczyk, Z.; Plichta, A.; Sobczak, M., Ring opening polymerization initiated by methylaluminoxane/AlMe3 complexes. Polymer 2006, 47 (4), 1081-1090.

29 Peng, S.; Peng, L.; Yi, C.; Zhang, W.; Wang, X., A novel synthetic strategy for preparing semi-aromatic components modified polyamide 6 polymer. J. Polym. Sci. Part A: Polym. Chem. 2018, 56 (9), 959-967.

30 Yilgor, I.; Yilgor, E. O. Waterproof, moisture vapor permeable polyurethane urea polymer comprising polycaprolactone and polydimethyl siloxane soft segments. U.S. Patent 5,461,122, October 24, 1995.

31 Albert0 Ballistreri, D. G., Mario Giuffrida, Giorgio Montaudo', Identification of the ions produced by fast atom bombardment mass spectrometry in some polyesters and polyamides Anal. Chem. 1987, 59 (17), 2024-2027.

32 Vitalini, L. M. G. M. E. S. S. R. D., Organotin-Mediated Synthesis of Macrocyclic Tetraesters. A Combined IH NMR Spectroscopy, Gel Permeation Chromatography, and Fast Atom Bombardment Mass Spectrometry Approach to Complete Product Analysis. Macromolecules 198922 (8), 3275-3280.

33 Peponi, L.; Navarro-Baena, I.; Sonseca, A.; Gimenez, E.; Marcos-Fernandez, A.; Kenny, J. M., Synthesis and characterization of PCL-PLLA polyurethane with shape memory behavior. Eur. Polym. J. 2013, 49 (4), 893-903.

34 Besghini, D.; Mauri, M.; Simonutti, R., Time Domain NMR in Polymer Science: From the Laboratory to the Industry. Appl. Sci. 2019, 9 (9), 1801-1834.

35 Tian, M. K. S. Y. Y., Energy Gaps and their Control in Thiophene - Based Polymers and Oligomers. In Handbook of Thiophene-based Materials: Applications in Organic Electronics and Photonics; John Wiley \& Sons, Ltd: New York, 2009; pp 341-364.

36 DFT calculations were performed under the level of (SMD)M06/6-311++G(d,p)-SDD//B3LYP-D3(BJ)/6-31G(d,p)-SDD by Gaussian program. See SI for computational details.

37 Edward L. Marshall, V. C. G., Henry S. Rzepa, A Computational Analysis of the Ring-Opening Polymerization of rac -Lactide Initiated by Single-Site â-Diketiminate Metal Complexes: Defining the Mechanistic Pathway and the Origin of Stereocontrol. J. Am. Chem. Soc. 2005, 127 (16), 60486051.

38 Jitonnom, J.; Molloy, R.; Punyodom, W.; Meelua, W., Theoretical studies on aluminum trialkoxide-initiated lactone ring-opening polymerizations: Roles of alkoxide substituent and monomer ring structure. Comput. Theor. Chem. 2016, 1097, 25-32.

39 Marlier, E. E.; Macaranas, J. A.; Marell, D. J.; Dunbar, C. R.; Johnson, M. A.; DePorre, Y.; Miranda, M. O.; Neisen, B. D.; Cramer, C. J.; Hillmyer, M. A.; Tolman, W. B., Mechanistic Studies of epsilon-Caprolactone Polymerization by (salen)AIOR Complexes and a Predictive Model for Cyclic Ester Polymerizations. ACS Catal. 2016, 6 (2), 1215-1224.

40 Wei, J.; Riffel, M. N.; Diaconescu, P. L., Redox Control of Aluminum Ring-Opening Polymerization: A Combined 
Experimental and DFT Investigation. Macromolecules 2017, 50 (5), 1847-1861.

41 Macaranas, J. A.; Luke, A. M.; Mandal, M.; Neisen, B. D.; Marell, D. J.; Cramer, C. J.; Tolman, W. B., Sterically Induced Ligand Framework Distortion Effects on Catalytic Cyclic Ester Polymerizations. Inorg. Chem. 2018, 57 (6), 3451-3457.

42 Mandal, M.; Luke, A. M.; Dereli, B.; Elwell, C. E.; Reineke, T. M.; Tolman, W. B.; Cramer, C. J., Computational Prediction and Experimental Verification of $\varepsilon$-Caprolactone RingOpening Polymerization Activity by an Aluminum Complex of an Indolide/Schiff-Base Ligand. ACS Catal. 2018, 9 (2), 885889.

43 Sattayanon, C.; Kungwan, N.; Punyodom, W.; Meepowpan, P.; Jungsuttiwong, S., Theoretical investigation on the mechanism and kinetics of the ring-opening polymerization of epsilon-caprolactone initiated by tin(II) alkoxides. J. Mol. Graphics Modell. 2013, 19 (12), 5377-5385

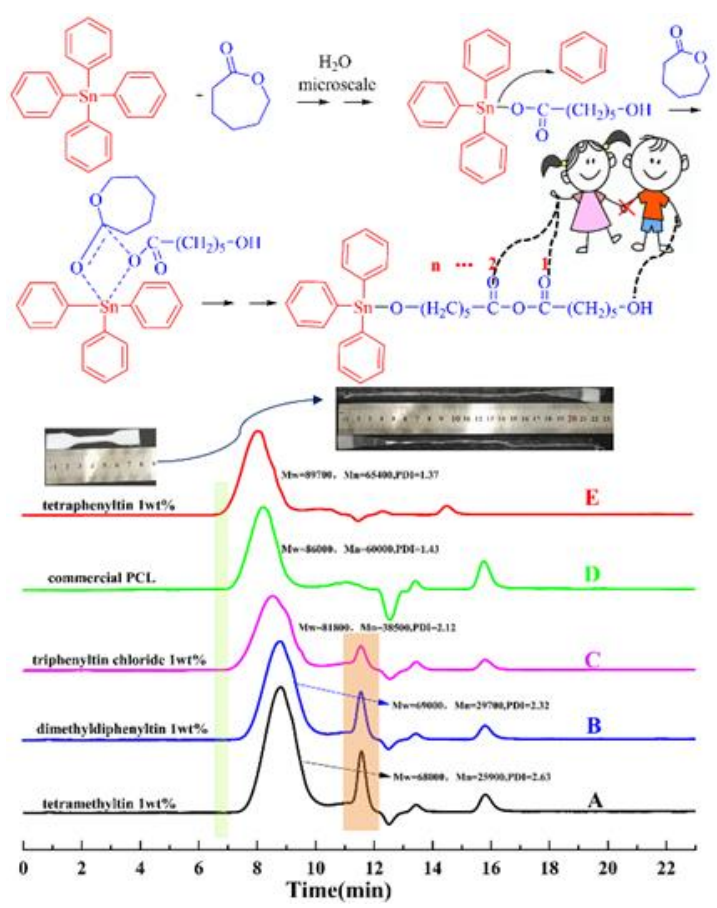

